\title{
Estimating Increased Electronic Laboratory Reporting Volumes for Meaningful Use: Implications for the Public Health Workforce
}

\author{
Brian E. Dixon ${ }^{1,2,3}$, P. Joseph Gibson ${ }^{4}$, Shaun J. Grannis ${ }^{2,5}$
}

1. School of Informatics and Computing, Indiana University, Indianapolis, IN

2. Center for Biomedical Informatics, Regenstrief Institute, Indianapolis, IN, USA

3. Center for Health Information and Communication, Department of Veterans Affairs, Veterans Health Administration, Health Services Research and Development Service CIN 13-416, Richard L. Roudebush VA Medical Center, Indianapolis, IN, USA

4. Health and Hospital Corporation of Marion County, Indianapolis, IN, USA

5. School of Medicine, Indiana University, Indianapolis, IN

\begin{abstract}
Objective: To provide formulas for estimating notifiable disease reporting volume from 'meaningful use' electronic laboratory reporting (ELR). Methods: We analyzed two years of comprehensive ELR reporting data from 15 metropolitan hospitals and laboratories. Report volumes were divided by population counts to derive generalizable estimators. Results: Observed volume of notifiable disease reports in a metropolitan area were more than twice national averages. ELR volumes varied by institution type, bed count, and by the level of effort required of health department staff. Conclusions: Health departments may experience a significant increase in notifiable disease reporting following efforts to fulfill meaningful use requirements, resulting in increases in workload that may further strain public health resources. Volume estimators provide a method for predicting ELR transaction volumes, which may support administrative planning in health departments.

Keywords: Clinical Laboratory Information Systems, Computerized Medical Record Systems, Disease Notification, Health Information Exchange, Health Manpower, Public Health Informatics

DOI: 10.5210/ojphi.v5i3.4939

Correspondence: bedixon@iupui.edu

Copyright $\odot 2013$ the author(s)

This is an Open Access article. Authors own copyright of their articles appearing in the Online Journal of Public Health Informatics. Readers may copy articles without permission of the copyright owner(s), as long as the author and OJPHI are acknowledged in the copy and the copy is used for educational, not-for-profit purposes.
\end{abstract}

\section{Introduction}

Electronic reporting of reportable diseases may increase significantly [1,2], and estimates of that increase will help prepare public health agencies. The Health Information Technology for Economic and Clinical Health (HITECH) Act authorized the Centers for Medicare and Medicaid 
Services (CMS) to incentivize the adoption of electronic health records (EHRs) [3], a program known generally as 'meaningful use' (MU) [4,5]. Stage 2 MU criteria require electronic submission of laboratory data for reportable disease cases from eligible hospitals to health departments. Case reporting from eligible providers may also increase, as Stage 3 criteria may require providers to use ELR for submission of data to public health [6].

Public health receives case information to monitor and contain disease transmission [7]. Responses to reported cases include simply logging the incident, contacting the clinician, verifying treatment, and full case investigation involving direct communication with patients and individuals having contact with the patient. Despite efforts to improve notifiable disease reporting completeness through efforts including electronic laboratory reporting (ELR) [8], health department processes still depend on manual, provider-initiated submission of information $[9,10]$.

While some health departments receive portions of their cases electronically [8], Stage 2 meaningful use requirements may increase electronic report volumes [1]. Consequently, health department workloads may increase since electronic methods can mitigate human barriers to improved reporting [11] leading to increased case reporting, an aim of meaningful use policies [12]. Estimating the volume of ELR submissions resulting from meaningful use can enable health departments to predict workload for epidemiologists, case investigators, and others processing case reports. However, few health departments have experience with high volume ELR, making estimation difficult.

\section{Methods}

The Indiana Network for Patient Care (INPC), a regional health information exchange, has been processing high volumes of ELR for over a decade [13-15]. The INPC processes over 500,000 daily transactions, representing $90 \%$ of laboratory results for the Indianapolis-Carmel Metropolitan Statistical Area (MSA). When a case meets reporting criteria, the INPC forwards the ELR information to state and local health departments. Similar reporting models are likely to be adopted by health departments around the nation. To support health department estimation of ELR volume, we examined current reporting rates per population and provider.

The INPC uses the Notifiable Condition Detector (NCD), an automated case-detection system developed at the Regenstrief Institute [16], to process clinical transactions from more than 40 INPC hospitals, laboratories and local ancillary service organizations. We previously described the NCD and its ability to detect and report suspected cases of notifiable disease to public health [11,17-19].

A convenience set of data between January 1, 2010 and December 15, 2011 for INPC institutions were extracted from the NCD for analysis [20]. Cases with laboratory results associated with reportable conditions as defined by Indiana law [21] were included in the analysis. We excluded duplicates of the same disease incidence for the same individual using the open source probabilistic linkage software package utilized by the INPC [22-24]. This analysis was approved by the Indiana University Institutional Review Board. 
Unique notifiable disease cases were divided by the 2010 U.S. census population data for the Indianapolis-Carmel MSA to obtain a general estimate of ELR rates. Because the number of patient days is readily available to other health departments wishing to leverage these results, we stratified notifiable disease cases from each facility using number of patient days. Hospitals report number of patient days to the CMS Healthcare Cost Report Information System (HCRIS) through approved Medicare Administrative Contractors.

Further, case investigators at the Marion County Public Health Department (MCPHD) used a consensus process to assign an expected level of effort for case investigation and follow-up associated with each reportable disease (see Table 1). MCPHD staff verify that patients receive treatment, initiate prophylaxis for patients' contacts (e.g., for meningitis or whooping cough), and monitor disease spread patterns; each disease requires varying combinations of these work processes. MCPHD staff enumerated their work processes and self-reported their level of effort for specific disease investigation tasks. Variation in reported workflow and levels of effort were resolved through discussion with study investigators. Study investigators first grouped ELR messages into disease classes using the U.S. Centers for Disease Control and Prevention (CDC) Reportable Conditions Mapping Table [25], then they assigned each disease class to levels based on the associated work processes and levels of effort reported by MCPHD staff. Level 1 represents cases requiring under 2 hours' work with minimal paperwork and rare contact investigation. Level 2 cases require approximately 3 hours' work with limited paperwork, patient interviews, and contact investigation. Level 3 cases require over 3 hours' work, detailed patient interviews, and some contact investigation. Level 4 cases require extensive contact investigation, patient interviews and provider follow-up.

\section{Results}

\section{Estimation using overall ELR counts and population}

The INPC reported 71,742 unique cases of suspected notifiable disease in the IndianapolisCarmel MSA during the two year time period. According to 2010 U.S. census data, the Indianapolis-Carmel MSA population is 1,834,672. Dividing the notifiable disease case count by the population produces a ratio of 1,955 ELR cases per 100,000 population per year.

\section{Estimation using number of patient days}

We paired notifiable disease reports with the corresponding hospital or network of hospitals in the Indianapolis-Carmel MSA. A total of 11 hospitals or hospital networks accounted for the 71,742 ELR reports. Dividing ELR report counts by the number of patient days for each year in the study period produced the ratios depicted in Figure 1. The average number of patient days was 89,012 with a minimum of 11,014 , a maximum of 357,985, and a standard deviation of 107,712. The average ratio of ELR reports to number of patient days per year was 0.028 with a minimum of 0.004 , a maximum of 0.094 , and a standard deviation of 0.029 . The county hospital, the first data point in Figure 1, reported the highest rate; all other hospitals are non-profit community hospitals. 


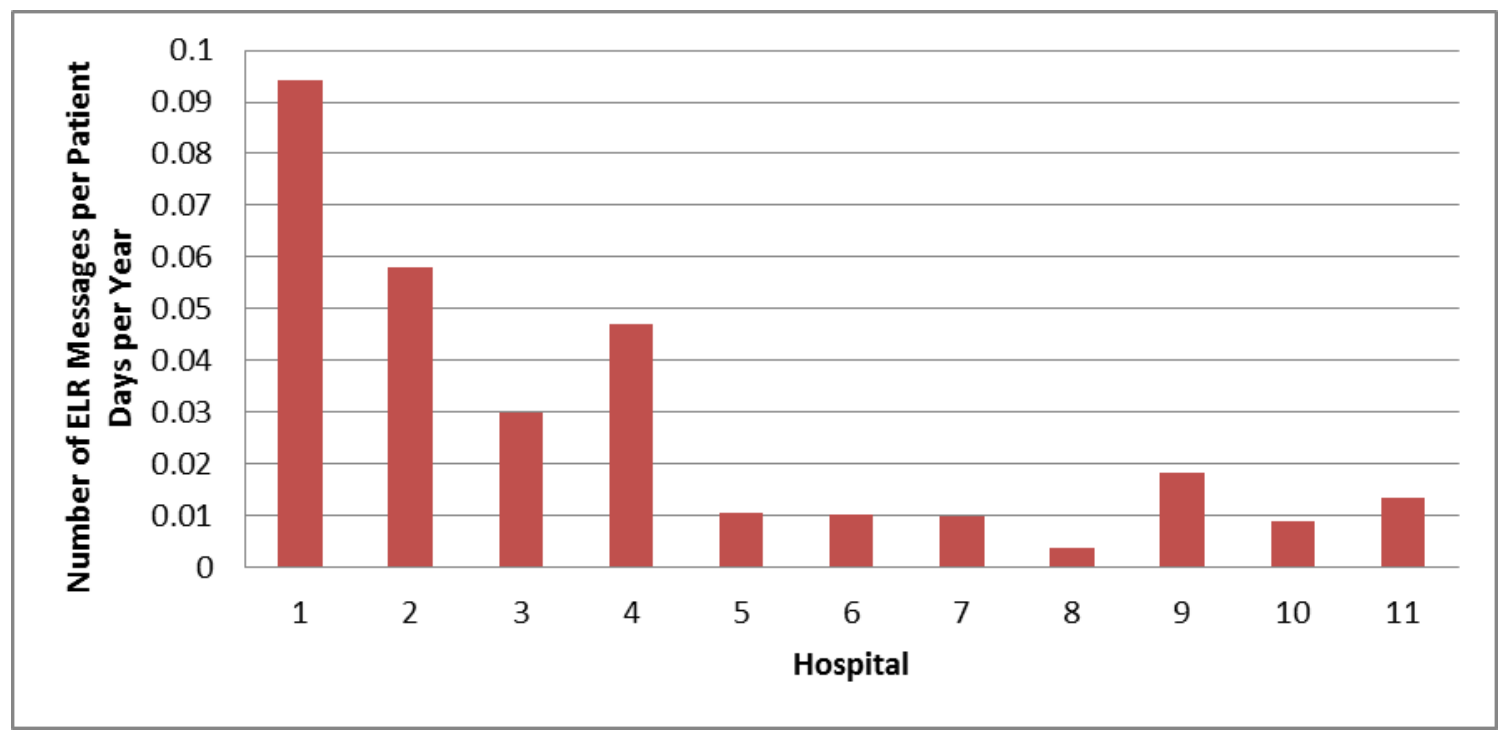

Figure 1: Comparison of ELR reports to patient days per hospital per year

\section{ELR messaging by disease classification}

We classified 60,094 ELR messages based on the disease-associated workload of MCPHD staff who perform follow-up tasks for reported cases, depicted in Table 1. While the majority of messages represent Level 2 conditions (49.6\%), Level 3 cases accounted for 34.9\%, and Level 4 totaled $11.2 \%$. Level 1 cases, which require minimal follow-up, represented just $4.3 \%$ of all reports.

Table 1 - ELR messages grouped by disease and estimated level of effort to perform local health department follow-up procedures.

\begin{tabular}{|l|l|l|l|l|}
\hline Disease and effort & $\begin{array}{l}\text { Count } \\
(\%)\end{array}$ & $\begin{array}{l}\text { Rate } \\
\text { per } \\
\mathbf{1 0 0 , 0 0 0} \\
\text { per } \\
\text { year }\end{array}$ & $\begin{array}{l}\text { MMWR } \\
\text { Rate } \\
\text { per } \\
\mathbf{1 0 0 , 0 0 0} \\
\mathbf{2 0 1 0}\end{array}$ & $\begin{array}{l}\text { MMWR } \\
\text { Rate } \\
\text { per } \\
\mathbf{1 0 0 , 0 0 0} \\
\mathbf{2 0 1 1}\end{array}$ \\
\hline $\begin{array}{l}\text { Level 4 effort: substantial contact } \\
\text { investigation, patient interview } \\
\text { and provider follow-up required }\end{array}$ & $\begin{array}{l}\mathbf{6 , 7 2 6} \\
\mathbf{( 1 1 . 2 \% )}\end{array}$ & $\mathbf{1 8 3 . 3 0}$ & & \\
\hline Human Immunodeficiency Virus & 3,452 & 94.08 & 11.64 & 11.41 \\
\hline Measles & 3,177 & 86.58 & 0.02 & 0.07 \\
\hline $\begin{array}{l}\text { Tuberculosis } \\
\text { Typhoid fever }\end{array}$ & 90 & 2.45 & 3.64 & 3.41 \\
\hline $\begin{array}{l}\text { Level 3 effort - over 3 hours: } \\
\text { Increased paperwork required, } \\
\text { patient }\end{array}$ & $\begin{array}{l}\mathbf{2 0 , 9 7 9} \\
\mathbf{( 3 4 . 9 \% )}\end{array}$ & $\mathbf{5 7 1 . 7 4}$ & & 0.13 \\
\hline
\end{tabular}




\begin{tabular}{|c|c|c|c|c|}
\hline moderate contact investigation & & & & \\
\hline Diphtheria & 124 & 3.38 & N/A & N/A \\
\hline Escherichia coli 0157 H7 infection & 1,306 & 35.59 & 1.78 & 1.96 \\
\hline Hantavirus & 10 & 0.27 & 0.01 & 0.01 \\
\hline Hepatitis A & 2,435 & 66.36 & 0.54 & 0.45 \\
\hline Hepatitis E & 10 & 0.27 & N/A & N/A \\
\hline Lead exposure & 11,208 & 305.45 & N/A & N/A \\
\hline Listeriosis & 7 & 0.19 & 0.27 & 0.28 \\
\hline Meningitis (fungal) & 1 & 0.03 & N/A & N/A \\
\hline Meningococcal Disease & 104 & 2.83 & 0.27 & 0.25 \\
\hline Mumps & 1,318 & 35.92 & 0.85 & 0.13 \\
\hline Mycobacterium non-Tb & 528 & 14.93 & N/A & N/A \\
\hline Pertussis & 314 & 8.56 & 8.97 & 6.06 \\
\hline Poliomyelitis & 4 & 0.11 & N/A & N/A \\
\hline Q Fever & 1 & 0.03 & 0.04 & 0.04 \\
\hline Rubella & 2,045 & 55.73 & 0.00 & 0.00 \\
\hline Shigellosis & 265 & 7.22 & 4.82 & 4.32 \\
\hline Syphilis & 1,298 & 35.37 & 14.93 & 14.90 \\
\hline Trichinosis & 1 & 0.03 & 0.00 & 0.00 \\
\hline $\begin{array}{l}\text { Level } 2 \text { effort, up to } 3 \text { hours: } \\
\text { Minimal paperwork and patient } \\
\text { interview, minimal contact } \\
\text { investigation }\end{array}$ & \begin{tabular}{|l|}
29,810 \\
$(49.6 \%)$
\end{tabular} & 812.41 & & \\
\hline Arbovirus & 11 & 0.30 & 0.37 & 0.28 \\
\hline Campylobacteriosis & 296 & 8.07 & N/A & N/A \\
\hline Chickenpox & 6,009 & 163.76 & 5.03 & 4.70 \\
\hline Chlamydia infection & 8,229 & 224.26 & 426.01 & 457.14 \\
\hline Cryptosporidiosis & 27 & 1.20 & 2.91 & 2.99 \\
\hline Dengue fever & 6 & 0.16 & 0.22 & 0.08 \\
\hline Ehrlichiosis & 5 & 0.14 & 0.85 & 0.83 \\
\hline Giardiasis & 54 & 1.47 & 6.45 & 5.42 \\
\hline Gonorrhea & 3,224 & 87.86 & \begin{tabular}{|l}
100.76 \\
\end{tabular} & 104.14 \\
\hline
\end{tabular}




\begin{tabular}{|c|c|c|c|c|}
\hline Haemophilus influenzae & 210 & 5.72 & 1.03 & 1.15 \\
\hline Hepatitis B & 7,033 & 191.67 & 1.10 & 0.94 \\
\hline Hepatitis C & 3,071 & 83.69 & 0.28 & 0.40 \\
\hline Hepatitis D & 3 & 0.08 & N/A & N/A \\
\hline Histoplasmosis & 164 & 4.47 & N/A & N/A \\
\hline Legionellosis & 446 & 12.15 & 1.09 & 1.36 \\
\hline Malaria & 1 & 0.03 & 0.58 & 0.56 \\
\hline Rickettsial infection & 2 & 0.05 & N/A & N/A \\
\hline Salmonellosis non-typhoid & 631 & 17.20 & 17.73 & 16.79 \\
\hline Streptococcus pneumoniae & 299 & 8.15 & 5.40 & 5.55 \\
\hline Tetanus & 86 & 2.34 & 0.01 & 0.01 \\
\hline Yersiniosis non-plague & 3 & 0.08 & N/A & N/A \\
\hline $\begin{array}{l}\text { Level } 1 \text { effort, <2 hours: Little } \\
\text { paperwork involved, rare contact } \\
\text { investigation }\end{array}$ & $\begin{array}{l}2,579 \\
(4.3 \%)\end{array}$ & 70.29 & & \\
\hline Cryptococcosis & 44 & 1.20 & 0.06 & 0.05 \\
\hline Influenza & 1,579 & 43.03 & N/A & N/A \\
\hline Lyme disease & 139 & 3.79 & 9.82 & 10.71 \\
\hline Streptococcus group B & 817 & 22.27 & N/A & N/A \\
\hline Grand Total & 60,094 & $1,637.73$ & & \\
\hline
\end{tabular}

\section{DISCUSSION}

Meaningful use ELR requirements will likely boost notifiable disease surveillance efforts, which may significantly increase the volume of reports. This is in turn can further burden the public health workforce [26]. We used data from an advanced health information ecosystem to impute population-based ELR-based reporting rates. These rates can inform future report volume projections in jurisdictions across the nation. Further, our case management workload model can enhance health department estimates of future case management workforce capacity needs.

The first estimator, a measure of total cases reported using ELR from multiple systems, reveals that approximately 20 unique cases of suspected notifiable disease were reported per 1,000 persons each year. This ELR estimator is notable given that it is the first such figure reported and more than double the national average of confirmed cases reported by the CDC [27]. Rates in other jurisdictions could be higher or lower given differences in regional disease burden as well as reporting laws. Regenstrief investigators previously found that compared with traditional, paper-based reporting methods, ELR may quadruple the public health case report volume [17]. 
In addition to using a population-based approach, we matched each ELR case to the hospital and hospital network that performed the laboratory test. This approach revealed variance in the number of case reports from each facility or network. According to the Agency for Healthcare Research and Quality's Healthcare Cost and Utilization Project (HCUP) Nationwide Inpatient Sample, there were 38.6 million inpatient stays in 2011 with a mean length of stay of 4.6 days [28]. Using the observed median ELR cases per patient day in this study, we estimate that approximately 5.1 million cases of suspected notifiable disease should be reported annually to U.S. health departments. This is nearly double the number of confirmed cases reported by CDC for 2010 [29] and on par with the two-fold increase originally observed by Effler et al. [30] following the introduction of ELR.

We further categorized ELR cases based on the perceived level of effort associated with reportable disease case investigation activities as shown in Table 1. Using this table, individual health departments can estimate impact based on their own division of labor. For example, MCPHD has separate teams for the management of HIV/AIDS, sexually transmitted infections, and all other infectious diseases. Each team possesses different training and experience. Health departments can extract estimated rates from this table to generate figures more meaningful to their specific approach to managing various notifiable diseases.

An increase in suspected notifiable disease reports would significantly impact local and state health departments' workload. Recent downsizing and budget cuts in health departments across the nation [31,32] implies that an increase in reports would likely place pressure on departments to do more with less. The data in Table 1 suggests that even a modest increase in overall reporting will necessitate a substantial increase in health department staff effort to validate, investigate, confirm and close cases. Thus the potential increased reporting from meaningful use may not only translate into an increase in overall case volume, but an increase in disease reports for which health departments currently allocate few resources. And while the HITECH legislation provided billions of dollars for health care providers to adopt EHRs, it provided only \$30 million for public health agencies to enhance their infrastructure to receive and analyze data from EHRs [33].

The anticipated increase in volume includes three types of notifiable disease cases. First are true positive reports involving new cases of notifiable disease that must be investigated with potential follow-up involving providers and patients as well as their contacts. The second type are false positive reports in which the NCD or similar automated algorithms inadvertently submits an ELR message to public health who later concludes the report does not meet the case definition for a notifiable disease. For example, the NCD leverages a modified version of the Negex information retrieval methodology [34] to identify instances where reportable conditions are mentioned in a negated context, e.g., "no evidence of MRSA". Occasionally the system fails to identify particularly complex negations such as, "positive evidence for MRSA is identified inconclusively." We previously reported very good sensitivity, specificity, and positive predictive values for the NCD [16]. Therefore we do not suspect such false positives may have artificially increased our reported volumes. Finally, there exists what we label as "true-false positive" reports in which the NCD or similar algorithm correctly submitted an ELR message to public health that meets local or state case definitions but is not ultimately reported to CDC as a new confirmed case. Note that in Table 1 there are over 7,000 cases of Hepatitis reported during a 
two-year time period. This is an elevated rate, yet the NCD correctly reported these messages to local health departments. Many of these cases involved repeat positive cases for patients who are already known to public health. The cases are repeatedly transmitted to public health in compliance with Indiana Administrative Code, which states positive hepatitis tests must be reported to public health. Therefore the NCD correctly flagged the ELR messages as positive and reported them to local health departments, requiring public health to devote resources to adjudicating duplicate results.

To manage the impending increase in suspected case volume via ELR, public health agencies should consider a range of strategies. Some departments may revise their investigation protocols, de-emphasizing certain conditions or classifications of certain diseases to streamline their workload. Others may seek to obtain additional personnel or shift personnel from other program areas. Policymakers, agency heads, and epidemiologists should further consider revisions to administrative codes and public laws that currently allow for true-false positive reports. Refining local case definitions to increase specificity could help both ELR senders and receivers reduce the report volume that must be triaged by local health departments. The estimators and data described in this analysis can help frame discussions regarding which strategies might be best given local policies, infrastructure and processes.

Public health informatics competencies, including analytics and data management methods, are likely to become increasingly important as they can support epidemiologists' need to incorporate automated methods for validating, classifying, and prioritizing reports to focus limited staff time on high-value case follow-up and data use; such prioritization of cases is currently a manual process in most agencies. These competencies are further important to implement and optimize receipt of ELR data from various clinical informatics systems. For example, the INPC facilitates ELR in a consistent way while other states receive ELR directly from providers [35]. Receipt of ELR messages from a variety of sources with distinct methods for identifying patients would require health departments to maintain a master person index to identify and process duplicate reports of notifiable disease. Public health informatics professionals should explore methods for helping agencies to improve reporting processes and capacity for ELR; the nation should continue to support initiatives that increase informatics training for the public health workforce [36].

\section{Limitations}

Our estimates of notifiable disease report volume were derived from ELR data produced by hospitals and other clinical data sources in a single state and represented principally medium- to large-sized hospitals. The estimation techniques described herein have yet to be validated by comparison with data from other jurisdictions. Actual increases in notifiable disease report volumes may differ in other states based on hospital size as well as technical capacity within state and local health departments. The impact of ELR on reporting may also vary due to state and local policies that govern disease reporting processes. However, almost all jurisdictions adhere to a nationally recommended list of reportable diseases; variation is relatively small [37]. ELR rates in this analysis were dependent on the Regenstrief NCD, which has been described previously [16]. Other health departments, providers, or informatics solutions may use different 
algorithms to identify suspected cases of notifiable disease, which could significantly alter the volume reported to public health authorities.

\section{Conclusion}

Adoption and use of health information technologies continues to increase in clinical organizations. Meaningful use incentives aim to further connect clinical systems to public health departments to improve reporting of notifiable disease. Health departments must not only prepare technically for the receipt of ELR information, but they must also prepare their operations and workforce capacity to manage a potentially significant increase in report volume. We described estimates suggesting that automated ELR methods could at least double the volume of suspected notifiable disease case reports. Together public health and informatics professionals should work to strengthen the public health infrastructure, developing and evaluating automated methods for assisting health departments with the anticipated reporting volume increases.

\section{Acknowledgements}

The authors would like to thank Bill Brand, MPH, of the Public Health Informatics Institute and the anonymous reviewers at the Journal for feedback on early drafts of this article.

\section{Competing interests}

The authors declare they have no real or perceived conflicts of interest.

\section{Funding}

This study was supported, in part, by a grant award (5R01HS020209) from the U.S. Agency for Healthcare Research and Quality. The article was further supported, in part, by the Department of Veterans Affairs, Veterans Health Administration, Health Services Research and Development Service CIN 13-416. Dr. Dixon is a Health Research Scientist at the Richard L. Roudebush Veterans Affairs Medical Center in Indianapolis, Indiana. The views expressed in this article are those of the authors and do not necessarily reflect the position or policy of the Agency for Healthcare Research and Quality, Department of Veterans Affairs, or the United States government.

\section{References}

1. Smith PF, Hadler JL, Stanbury M, Rolfs RT, Hopkins RS. 2013. "Blueprint version 2.0": updating public health surveillance for the 21st century. J Public Health Manag Pract. 19(3), 231-39. PubMed http://dx.doi.org/10.1097/PHH.0b013e318262906e

2. Kirkwood J, Jarris PE. 2012. Aligning health informatics across the public health enterprise. J Public Health Manag Pract. 18(3), 288-90. PubMed http://dx.doi.org/10.1097/PHH.0b013e31824eb919

3. The American Recovery and Reinvestment Act of 2009, House of Representatives, 111th Congress Sess. (2009). 
4. Centers for Medicare \& Medicaid Services. Medicare and Medicaid Programs; Electronic Health Record Incentive Program--Stage 2. Federal Register [Internet]. 2012 [cited 2012 August 24]. Available from: http://www.ofr.gov/OFRUpload/OFRData/2012-21050_PI.pdf.

5. Centers for Medicare and Medicaid Services. Meaningful Use. Baltimore, MD: Centers for Medicare \& Medicaid Services; 2013 [updated Aug 23; cited 2013 Aug 27]; Available from: https://www.cms.gov/Regulations-and-Guidance/Legislation/EHRIncentivePrograms/Meaningful_Use.html.

6. Office of the National Coordinator for Health Information Technology. Health Information Technology; HIT Policy Committee: Request for Comment Regarding the Stage 3 Definition of Meaningful Use of Electronic Health Records (EHRs). Washington, DC: Department of Health \& Human Services, U.S.; 2012 [cited 2013 Aug 27]; Available from: http://www.regulations.gov/\#!documentDetail;D=HHS-OS-2012-0007-0002.

7. Lombardo JS, Buckeridge DL, eds. Disease Surveillance: A Public Health Informatics Approach. Hoboken: John Wiley \& Sons; 2007.

8. Turner K, Ferland L. 2011. State electronic disease surveillance systems --- United States, 2007 and 2010. MMWR Morb Mortal Wkly Rep. 60(41), 1421-23. PubMed

9. Dixon BE, Jones JF, Grannis SJ. 2013. Infection preventionists' awareness of and engagement in health information exchange to improve public health surveillance. Am J Infect Control. 41(9), 787-92. PubMed http://dx.doi.org/10.1016/j.ajic.2012.10.022

10. Jones NF, Calder L. eNotification: Adapting eReferral for Public Health Notifiable Disease Reporting in New Zealand. Healthcare informatics research. 2012;18(3):225-30.

11. Overhage JM, Suico J, McDonald CJ. 2001. Electronic laboratory reporting: barriers, solutions and findings. $J$ Public Health Manag Pract. 7(6), 60-66. PubMed http://dx.doi.org/10.1097/00124784200107060-00007

12. Savel TG, Foldy S. 2012. The role of public health informatics in enhancing public health surveillance. MMWR Surveill Summ. 61, 20-24. PubMed

13. Biondich PG, Grannis SJ. 2004. The Indiana network for patient care: an integrated clinical information system informed by over thirty years of experience. J Public Health Manag Pract. Suppl, S81-86. PubMed http://dx.doi.org/10.1097/00124784-200411001-00013

14. Zafar A, Dixon BE. 2007. Pulling back the covers: technical lessons of a real-world health information exchange. Stud Health Technol Inform. 129(Pt 1), 488-92. PubMed

15. Grannis SJ, Biondich PG, Mamlin BW, Wilson G, Jones L, et al. 2005. How disease surveillance systems can serve as practical building blocks for a health information infrastructure: the Indiana experience. AMIA Anпи Symp Proc. 286-90. PubMed

16. Fidahussein M, Friedlin J, Grannis S. Practical Challenges in the Secondary Use of Real-World Data: The Notifiable Condition Detector. AMIA Annu Symp Proc.

17. Overhage JM, Grannis S, McDonald CJ. 2008. A comparison of the completeness and timeliness of automated electronic laboratory reporting and spontaneous reporting of notifiable conditions. Am J Public Health. 98(2), 344-50. PubMed http://dx.doi.org/10.2105/AJPH.2006.092700

18. Dixon BE, McGowan JJ, Grannis SJ. Electronic laboratory data quality and the value of a health information exchange to support public health reporting processes. AMIA Annu Symp Proc. 2011;2011:322-30.

19. Dixon BE, Grannis SJ, Revere D. 2013. Measuring the impact of a health information exchange intervention on provider-based notifiable disease reporting using mixed methods: a study protocol. BMC Med Inform Decis Mak. 13(1), 121. PubMed http://dx.doi.org/10.1186/1472-6947-13-121 
20. Gichoya J, Gamache RE, Vreeman DJ, Dixon BE, Finnell JT, Grannis S. An Evaluation of the Rates of Repeat Notifiable Disease Reporting and Patient Crossover Using a Health Information Exchange-based Automated Electronic Laboratory Reporting System. AMIA Annu Symp Proc. 2012;2012:1229-36.

21. Indiana Administrative Code. Sect. 410 IAC 1-2.3-47 Reporting requirements for physicians and hospital administrators (2013).

22. Grannis S EJ, Ribeka N RecMatch: Probabilistic Patient Record Matching (Version 1.0) [Software]. 2008.

23. Grannis SBP, Downs S, Shelley M, Anand V, Egg J. Leveraging Open-Source Matching Tools and Health Information Exchange to Improve Newborn Screening Follow-up. Public Health Information Network AnnuSymp Proc Atlanta, GA. 2008.

24. Zhu VJ, Overhage MJ, Egg J, Downs SM, Grannis SJ. 2009. An empiric modification to the probabilistic record linkage algorithm using frequency-based weight scaling. Journal of the American Medical Informatics Association: JAMIA. 16(5), 738-45. PubMed http://dx.doi.org/10.1197/jamia.M3186

25. Gamache RE, Dixon BE, Grannis S, Vreeman DJ. Impact of selective mapping strategies on automated laboratory result notification to public health authorities. AMIA Annu Symp Proc. 2012;2012:228-36.

26. Foldy S. Health Information Technology: Promises and Challenges for Disease Prevention \& Control. [Presentation] Atlanta, GA: National Assocation of City and County Health Officials; 2011 [cited 2013 Aug 27]; Available from: http://www.naccho.org/advocacy/healthreform/upload/Foldy_Plenary_PTHC_June21.pdf.

27. Centers for Disease Control and Prevention. 2011. Summary of notifiable diseases: United States, 2009. MMWR Morb Mortal Wkly Rep. 58(53), 1-100. PubMed

28. Pfuntner A, Wier LM, Elixhauser A. Overview of Hospital Stays in the United States, 2011. HCUP Statistical Brief \#166. November 2013. Agency for Healthcare Research and Quality, Rockville, MD. Available from: http://www.hcup-us.ahrq.gov/reports/statbriefs/sb166.pdf.

29. 2012. Summary of notifiable diseases--United States, 2010. MMWR Morb Mortal Wkly Rep. 59(53), 1-111. PubMed

30. Effler P, Ching-Lee M, Bogard A, Ieong MC, Nekomoto T, et al. 1999. Statewide system of electronic notifiable disease reporting from clinical laboratories: comparing automated reporting with conventional methods. JAMA. 282(19), 1845-50. PubMed http://dx.doi.org/10.1001/jama.282.19.1845

31. Krisberg K. 2010. Budget cuts straining capacity of public health departments: Services in demand. Nations Health. 40(4), 1-16.

32. Brickman Bhutta C. Local Health Department Job Losses and Program Cuts: Findings from the January 2012 Survey. Washington, DC: National Association of City and County Health Officials, 2012 May. Report No.

33. Lenert L, Sundwall DN. 2012. Public health surveillance and meaningful use regulations: a crisis of opportunity. Am J Public Health. 102(3), e1-7. http://dx.doi.org/10.2105/AJPH.2011.300542

34. Chapman WW, Bridewell W, Hanbury P, Cooper GF, Buchanan BG. 2001. A simple algorithm for identifying negated findings and diseases in discharge summaries. J Biomed Inform. 34(5), 301-10. PubMed http://dx.doi.org/10.1006/jbin.2001.1029

35. Dixon BE, Siegel JA, Oemig TV, Grannis SJ. 2013. Electronic health information quality challenges and interventions to improve public health surveillance data and practice. Public Health Rep. 128(6), 546-53. $\underline{\text { PubMed }}$ 
36. Massoudi BL, Goodman KW, Gotham IJ, Holmes JH, Lang L, et al. 2012. An informatics agenda for public health: summarized recommendations from the 2011 AMIA PHI Conference. J Am Med Inform Assoc. 19(5), 688-95. PubMed http://dx.doi.org/10.1136/amiajnl-2011-000507

37. Centers for Disease Control and Prevention. Notice to Readers: NNDSS Tables Have Updated 'N' Indicators for 2011-2013. Atlanta, GA: MMWR; 2013 [updated Mar 29; cited 2013 Sep 1]; Available from: http://wwwn.cdc.gov/nndss/document/SRCA_FINAL_REPORT_2006-2012_final.xlsx. 